\title{
Survey of sexual satisfaction in married men in Sanandaj in 2020
}

\author{
Naseh Ghaderi ${ }^{1}$, Fazlollah Ghofranipour ${ }^{2}$, Fatemeh Zarei $^{3}$ \\ 1-PhD Student, Department of Health Education and Health Promotion, Tarbiat Modares University, Tehran, Iran. \\ 2- Professor, Department of Health Education and Health Promotion, Tarbiat Modares University, Tehran, Iran \\ (Corresponding Author). $\quad$ E-mail: Ghofranf@modares.ac.ir \\ 3- Assistant professor, Department of Health Education and Health Promotion, Tarbiat Modares University, Tehran, \\ Iran.
}

Received: 24/11/2021

Accepted: 15/01/2022

\begin{abstract}
Introduction: Sexual activity and the resulting satisfaction are among the major features of marital life, paying due attention to which will probably guarantee family survival and health.

Aim: Given the important role of men in marital sexual satisfaction and the focus of previous studies on sexual satisfaction among women, the aim of present study was to investigate the status of sexual satisfaction among married men in Sanandaj in 2020.

Method: The present descriptive cross-sectional study was conducted within the period of 20192020. The statistical population included all married men in Sanandaj, who entered the present study and were selected via systematic random sampling in 2019. The data collection tool was the Larson's Sexual Satisfaction Questionnaire, the validity of which had been already confirmed by experts, with its reliability having been confirmed by the Cronbach's alpha of 0.7. Data were analyzed by SPSS Statistics version 20 using descriptive analysis methods, including the mean, standard deviation, and relative frequency percentage.

Results: The participants mean age was $33.86 \pm 4.55$. Besides, the majority of the men reported poor $(43.1 \%)$ and moderate (53.9) sexual satisfaction. Furthermore, the mean and standard deviation of sexual satisfaction in the married men in Sanandaj were estimated at 71.02 \pm 6.28 .

Conclusion: The results indicate poor to moderate levels of sexual satisfaction in men. Thus, it is suggested that necessary educational programs and interventions be provided to increase married men's awareness of satisfactory sex through trainings provided at sexual health counseling centers.
\end{abstract}

Keywords: Sexual satisfaction, Men, Marriage

How to cite this article: Ghaderi N, Ghofranipour F, Zarei F. Survey of sexual satisfaction in married men in Sanandaj in 2020. Shenakht Journal of Psychology and Psychiatry. 2022; 8 (6): 1-9 .URL: http://shenakht.muk.ac.ir/article-1-1347-en.pdf

Copyright ( 92018 the Author (s). Published by Kurdistan University of Medical Sciences. This is an open access article distributed under the terms of the Creative Commons Attribution-Non Commercial License 4.0 (CCBY-NC), where it is permissible to download, share, remix, transform, and buildup the work provided it is properly cited. The work cannot be used commercially without permission from the journal. 


\title{
بورسى وضعيت رضايت جنسى در مردان متأهل شهر سندج در سال وج
}

\author{
ناصح قادرى '، فضل لل غفر انى يور'، فاطمه زارعى \\ ا.دانشجوى دكترى، گروه آموزش بهداشت و ارتقاء سلامت، دانشخاه تربيت مدرس، تهران، ايران.

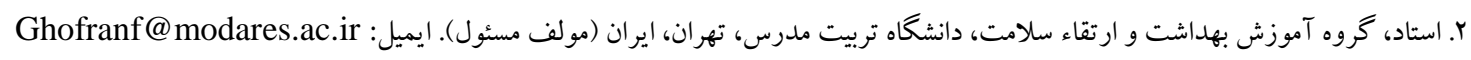

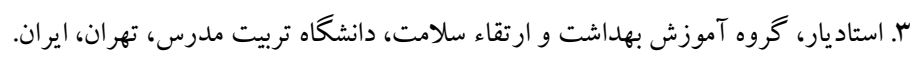

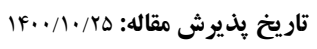

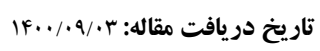

جكيده

مقدمه: فعاليت جنسى و رضايت حاصل از آن يكى از ويز گیىهاى مهم زندگى زناشويى است؛ كه توجه به آن، مى تواند بقا و سلامت خانواده را تضمين كند.

هدف: با توجه به نقش مهم مردان در رضايت جنسى زناشويى و تمركز بيشتر مطالعات يِيشن بر رضايت جنسى زنان، مطالعه حاضر با

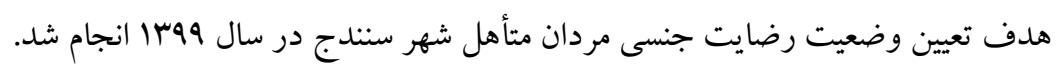

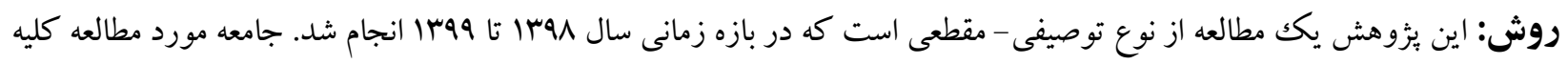

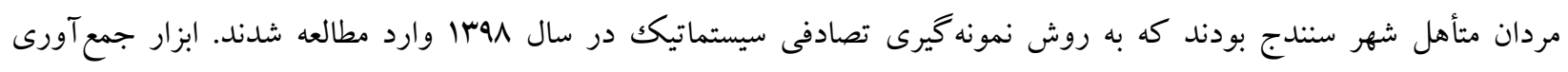

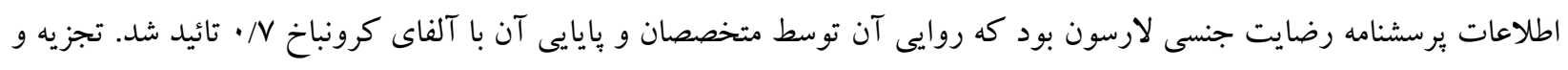

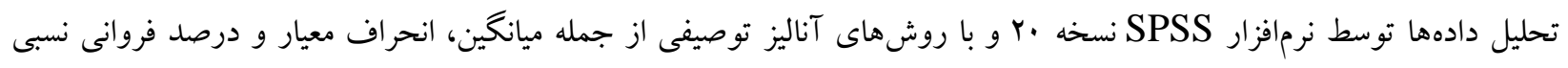
انجام شد.

يافته ها: ميانگين سنى افراد مورد مطالعه S

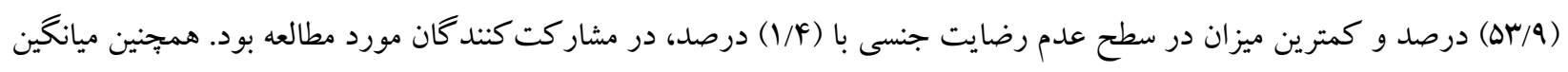

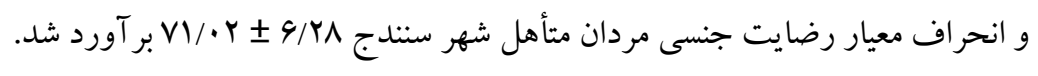

نتيجه كيرى: با توجه به اينكه نتايج ميزان رضايت جنسى مردان را در سطح كم تا متوسط نشان داد، ييشنهاد مىشود كه برنامهها و

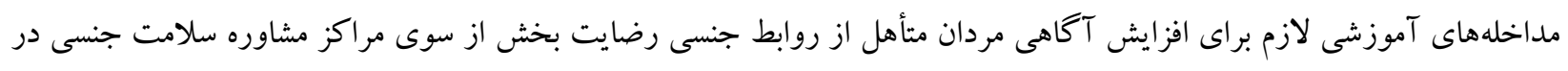
نظر كرفته شود.

كليدوازهها: رضايت جنسى، مردان، تأهل 
مانند تعداد مقاربتها و تجربه ارگاسم را در رضايت

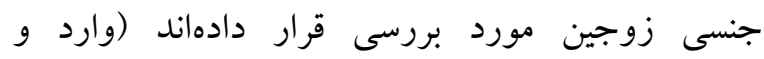

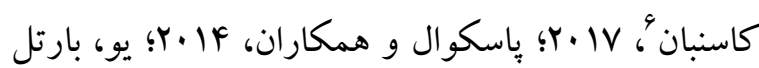

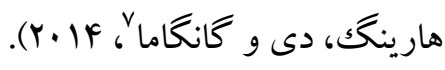
رضايت جنسى مىتواند به طور مستقيم يا غير مستقيم بر بسيارى از جنبه هاى زندگى زوجين تأثير گذار باشند (محبى، كمالى فرد، برزنجه عطرى و صفاييان، اجهاب). عدم رضايت جنسى مىتواند موجب كاهش بىثباتى در روابط زناشويى، اختلال عملكرد جنسى (يو و همكاران،

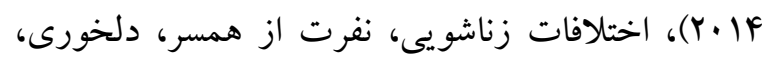
عدم اعتماد به نفس، احساس انتقام، خيانت زناشويى شود

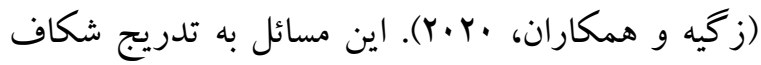

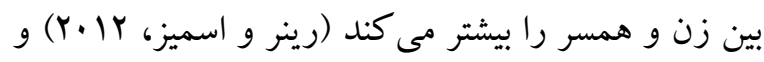
نهايتاً مىتواند منجر به طلاق شود (دين و همكاران،

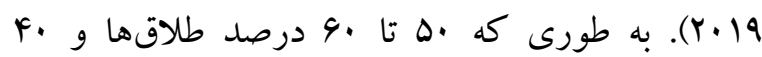
درصد خيانتها و ارتباطات خارج از ارتباط زناشويى، مربوط به عدم رضايت جنسى زناشويى است (بوزاكى،

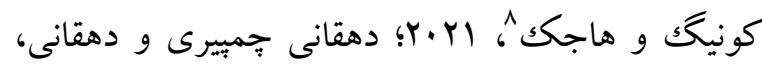
.r.r.r. مرقاتى خويى، 91/1؛ شافى عبدى، هنريروران، تبريزى و

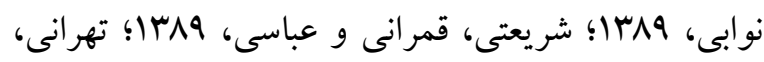
فرهمند، مهر ابى، افضلى و عابدينى، •وسم(). مطالعات بسيارى به بررسى نارضايتى جنسى و عوامل

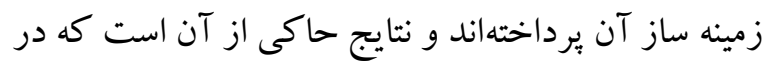
سطح جهانى نارضايتى جنسى در زنان بيشتر از مردان

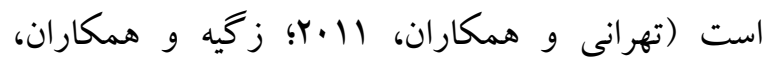
.Y.Y. . . تعدادى از مطالعات، شواهد متناقضى در رابطه با

6. Ward DA \& Kassenbaum GG

7- Yoo H, Bartle-Haring S, Day RD \& Gangamma R

${ }^{8}$ - Buczak-Stec E, Konig H-H \& Hajek A

9- Kim O \& Jeon HO
مقدمه

فعاليت جنسى و رضايت' حاصل از آن يكى از اساسىترين نيازهاى انسان است (شاه سياه، بوطلانى،

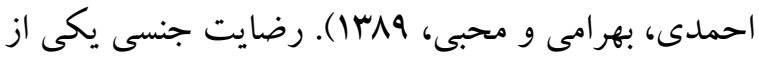
مهم ترين شاخص هاى ازدواج موفق است كه مىتواند بقا و سلامت خانواده را تضمين كند (غفرانى يور، امين شكروى و تر كاشوند، هوبا). رضايت جنسى را مىتوان به عنوان قضاوت فرد از ارزيابىهاى ذهنى مثبت و لذتبخش از رابطه جنسى با فرد ديخر تعريف كرد. تجربه جنين احساس خوب و مثبتى منجر به اركاسم هيجانانگيزى مى كردد كه در اغلب موارد با رضايت از رابطه جنسى همراه است (ياسكوال، نارسيو و بريريا'،

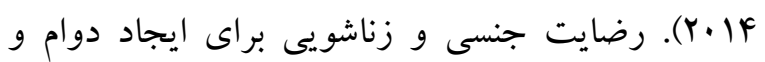
بيوندهاى خانو ادكى قوى ضرورى است. تحقيقات نشان داده است كه شادى زناشويى تأثير مثبتى بر رضايت جنسى دارد به طورى كه افزايش شادى زناشويى مى تواند باعث افزايش رضايت جنسى در افراد شود (خمسه، زهراكار و محسن زاده، هوب(1).

مطالعات مختلف نقش عوامل متعددى از جمله عوامل جمعيت شناختى سن، جنس، سطح تحصيلات و عقايد دينى (ياسكوال و همكاران، Y F (Y)، عوامل روانى مثل

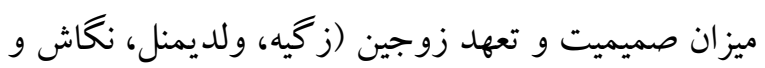

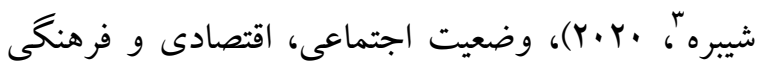

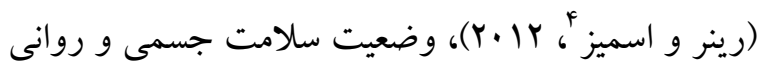

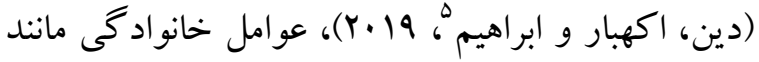
طول مدت ازدواج، تعداد فرزندان و سبكك فرزنديرورى، دانش و نكرش جنسى و در نهايت جنبههاى جسمى رابطه

\footnotetext{
1- Sexual satisfaction

2. Pascoal PM, Narciso IdSB \& Pereira NM

3 - Zegeye B, Woldeamanuel G, Negash W \& Shibre G

4 - Rainer H \& Smith I

5- Din HM, Akahbar SAN \& Ibrahim R
} 
رضايت جنسى مردان متأهل شهر سندج در سال 99

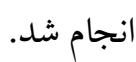

روش

اين يزوهش يكك مطالعه از نوع توصيفى - مقطعى بود. جامعه مورد مطالعه شامل تمامى مردان متأهلى بودند كه

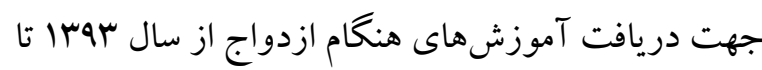
يوسا به مركز مشاوره ازدواج شهرستان سنندج مراجعه

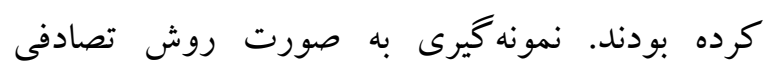

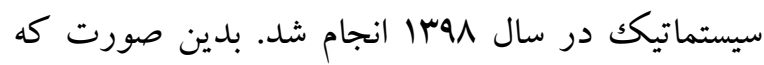
ابتدا فهرستى ( .... نفرى) از مردان مراجعه كننده براى

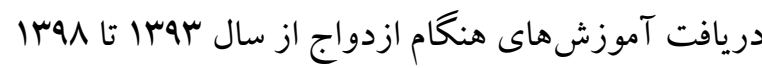
1. تهيه شد، سبس به طور منظم از هر صفحه ليست نفرى، نفر هشتم انتخاب گرديد. با توجه به نتايج مطالعات

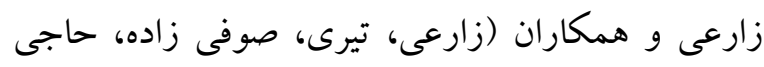

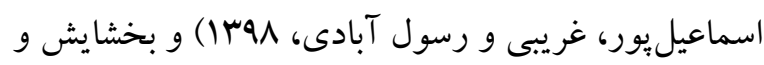
همكاران (بخشايش و مرتضوى، وN1|) همبستخى بين رضايت زناشويى و رضايت جنسى برابر با \&/· بود و با در

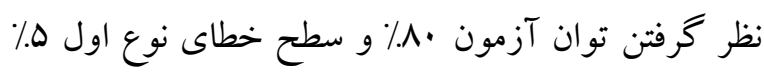
تعداد •سش نفر تخمين زده شد كه با احتساب • (\% احتمال ريزش احتمالى و به منظور بالا بردن دقت مطالعه، حجم

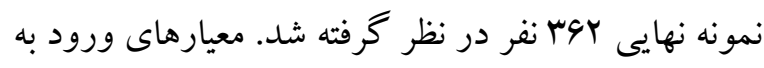
مطالعه شامل: سن بالاى 1/ سال و عدم اختلاف سنى بيش از ها سال، عدم مشكل حاد زناشويى و مراجعه براى

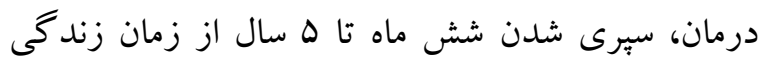
زناشويى، داشتن حداقل تحصيلات ابتدايى و توانايى خو اندن و نوشتن بود. همجِنين معيارهاى خروج از مطالعه نيز شامل، عدم تمايل به شر كت در مطالعه و تكميل ناقص يرسنامه بود.
رضايت جنسى ارائه دادهاند و ضمن تأكيد بر تفاوتهاى

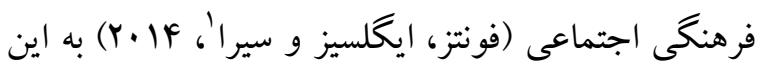
نتيجه رسيدهاند كه رضايت جنسى زنان بالاتر از مردان

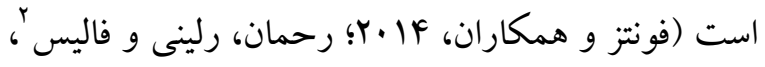
(Y) (Y). ميزان نارضايتى جنسى در خاورميانه نيز در مردان

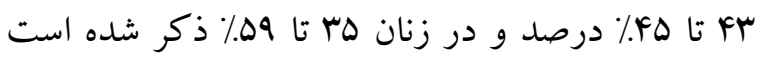

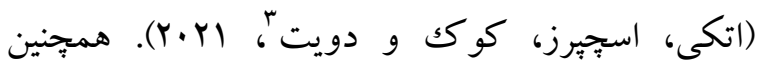
رضايت جنسى نقش مهمى در بيشخيرى از رفتارهاى جنسى برخطر، بيمارىهاى روانى جدى، جنايات اجتماعى و در نهايت طلاق دارد (زگيه و همكاران،

. $(Y \cdot Y$.

رضايت جنسى مىتواند نقش كليدى را در ساز گارى

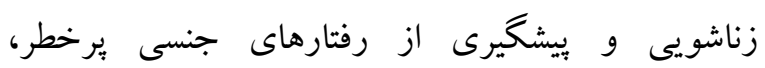
بيمارىهاى روانى جدى، جنايات اجتماعى و در نهايت طلاق ايفا كند (بشارت و رفيع زاده، هوسا؛ ميدان و

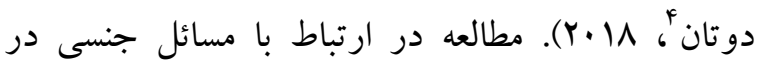
ايران با توجه به وضعيت و ساختارهاى فرهنگى اجتماعى با دشوارىهاى فراوانى روبروست (رحمانى، مرقاتى خويى، مقدم، زارعى، منتظرى و حاجى زاده،

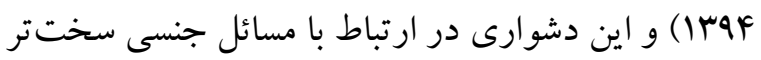
هم مىشود. از آنجايى كه طبق بررسى ما، اكثر مطالعات به بررسى فاكتورهاى مرتبط با رضايت جنسى در زنان برداختهاند (مرقاتى خويى، معينى، براتى، سلطانيان، شاهييرى و قليعها، 94س|) و با توجه به اهميت رضايت جنسى زوجين و به خصوص نقش مهم مردان در رضايت جنسى زناشويى؛ لذا مطالعه حاضر با هدف تعيين وضعيت

\footnotetext{
1- Del Mar Sanchez-Fuentes M, Santos-Iglesias P \& Sierra JC

2. Rehman US, Rellini AH \& Fallis E

3 - Attaky A, Schepers J, Kok G \& Dewitte M

4- Gewirtz-Meydan A \& Finzi-Dottan R
} 
براساس طيف ليكرت (هرگز، به ندرت، گاهى اوقات، بيشتر اوقات، هميشه) گنجانده شده است. براساس اين

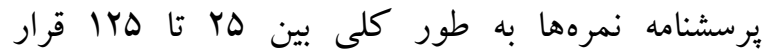
مى گيرند و طبقهبندى رضايت جنسى به سطوح عدم رضايت جنسى (نمره كمتر از • له)، رضايت كم (نمره بين اله تا VD)، رضايت متوسط (نمره بين V9 تا...1) و رضايت زياد (نمره بالاتر از 1.1 به بالاست) انجام مىشود. اين برسشنامه در مطالعه بهرامى و همكاران در سال عqrا در زوجين ايرانى بومىسازى و روانسنجى شد ئرس (بهرامى، شريفى، سليمانى و حقدوست، ه9ب1). ثبات درونى اين برسشنامه با احتساب ميزان آلفاى كرونباخ V/ • محاسبه شد. همجيْنين روايى سازه اين برسشنامه با استفاده از تحليل عاملى اكتشافى در \& عامل (تمايل به برقرارى

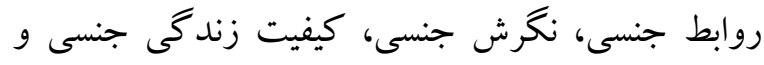
ساز گارى جنسى) مورد تائيد قرار كرفت.

يافتهها

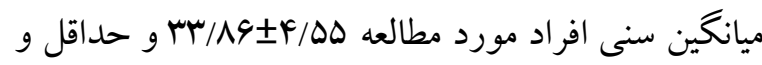
حداكثر سن آنها به ترتيب سY و FN سال بود. بيشتر افراد

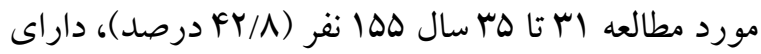
تحصيلات كارشناسى .19 نفر (FF/Y درصد)، داراى شغل آزاد 9Y/A) درصد)، فاقد فرزند r/1 نفر (19/•ه درصد)، مدت زمان

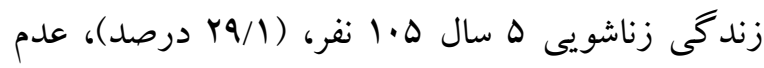
مصرف دخانيات YrV نفر (GT/V درصد) و داراى سابقه بيمارى سس نفر (Y9 درصد) بودند. يافتههاى بدست آمده از ميزان فراوانى و درصد رضايت جنسى در جدول شماره ا درج گرديده است.
پس از انتخاب نمونههاى مطالعه، با تماس تلفنى با افراد در ابتدا شرح مختصرى درباره موضوع مطالعه و اهداف آن بيان شد. سبس با در نظر گرفتن معيارهاى ورود و خروج مطالعه، از مردان انتخاب شده جهت تكميل برسشنامها، به مركز مشاوره ازدواج شهرستان سنندج به صورت حضورى و براى شركت در مطالعه دعوت به عمل آمد. در صورت داشتن تمايل افراد انتخاب شده براى شركت در مطالعه، ابتدا فرم رضايتنامه كتبى را جهت شركت در مطالعه تكميل كردند و سيس برسشنامه اطلاعات فردى و رضايت جنسى لارسون به صورت حضورى در اختيارشان قرار گرفت و تكميل نمودند. به افراد اطمينان داده شد كه اطلاعاتشان محرمانه مىماند. براى تجزيه و تحليل دادهها از روشهاى آناليز توصيفى

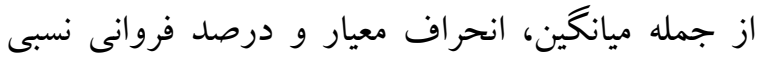
توسط نرمافزار SPSS نسخه ·ب انجام شد.

ابزار يرسشنامه اطلاعات جمعيت شناختى: شامل ها سؤال از جمله: سن فرد و همسر، مدت سبرى شده از ازدواج، تعداد فرزند، وضعيت نوع سكونت در منزل، سطح تحصيلات فرد و همسر، وضعيت شغلى فرد و همسر، جندمين بار ازدواج فرد و همسر، داشتن بيمارى فرد و همسر، مصرف دخانيات، مشروبات الكلى يا مواد مخدر

$$
\text { در فرد و همسر بود. }
$$

يرسشنامه رضايت جنسى لارسون ؛ براى سنجش ميزان رضايت جنسى از يرسشنامه لو سؤالى رضايت جنسى لارسون (لارسون، اندرسون، هلمان و نيمان؛

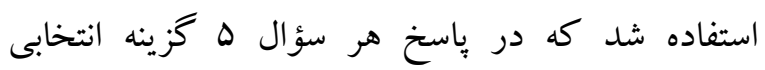

\footnotetext{
1. Larson sexual satisfaction questionnaire LSSQ

2 - Larson JH, Anderson SM, Holman TB \& Niemann BK
} 


\begin{tabular}{|c|c|c|c|c|}
\hline درصد فراوانى تراكمى & درصد & فراوانى & & متغير \\
\hline $1 / f$ & $1 / 4$ & $\Delta$ & اصلاً ندارند & \multirow{5}{*}{ رضايت جنسى } \\
\hline$F F / D$ & $\mathrm{kr} / \mathrm{l}$ & 109 & ضعيف & \\
\hline $9 \wedge / r$ & $\Delta r / q$ & 190 & متوسط & \\
\hline \multirow[t]{2}{*}{$1 \ldots$} & $1 / \mathrm{V}$ & 9 & 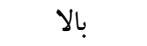 & \\
\hline & $1 \ldots$ & raY & كل & \\
\hline
\end{tabular}

و همكاران (هوبا) نيز ميانگين رضايت جنسى مردان را rN/DI بيان كردند كه كمتر از مطالعه حاضر بود. شايد بتوان كفت همسو نبودن نتايج حاصل از مطالعات بيان شده با مطالعه حاضر، انتخاب ابزار و واحدهاى بثزوهش بـ بـ متفاوت (برسشنامه وضعيت جنسى كلومبو كى) بود.

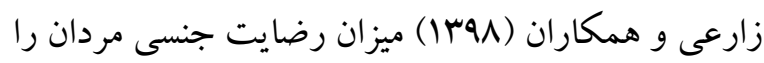
يايين گزارش كردند كه با نتايج مطالعه حاضر ناهمسو است. شايد بتوان كفت تفاوت هاى مشاهده شده در ميزان رضايت جنسى ممكن است به دليل عوامل فرهنگى و ونت مذهبى، قوانين و هنجارهاى حاكم بر جامعه و خانواده

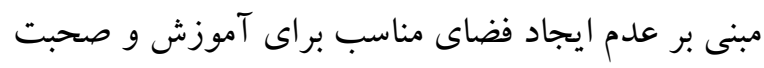
در مورد مسائل جنسى و امكان دسترسى به اطلاعات مورد نياز براى داشتن يكك ارتباط جنسى مطلوب باشد.

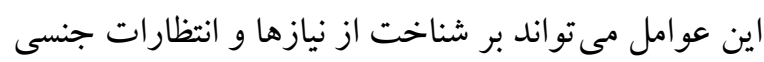
زوجها و رضايت جنسى آنها مؤثر باشد. برخلاف نتايج مطالعه حاضر، كالويلوّم و همكاران

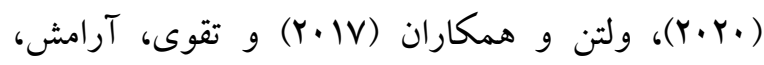

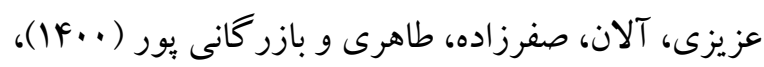

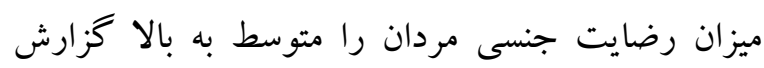
كردند كه مىتواند به دليل تفاوت در مدت زمان سبرى شده از ازدواج و ميانگين سنى آنها باشد. افراد تازه ازدواج كرده و با سن بايين معمولاً زمان بيشترى را باهم مى كذارند و ارتباط جنسى در سالهاى نخست ازدواج

${ }^{3}$ - Calvillo C, Sanchez-Fuentes MD \& Sierra JC
براساس نتايج حاصل از جدول ا فراوانى و درصد نمرات كسب شده براى جمعيت مورد مطالعه جهت سنجش رضايت جنسى با حداقل نمره ·F و حداكثر هY ال، ميانكين

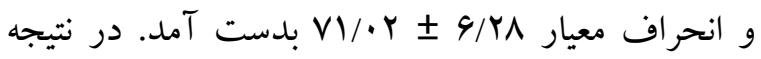
مىتوان كفت كه از زير طبقات متغير رضايت جنسى، بيشترين ميزان مربوط به سطح رضايت جنسى، متوسط با

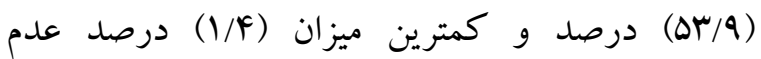
رضايت جنسى در مشار كت كنند كان مورد مطالعه بود. هدف از مطالعه حاضر تعيين وضعيت رضايت جنسى در مردان متأهل بود. نتايج حاصل از اين مطالعه نشان داد كه بيشتر افراد مورد مطالعه اس تا ها ساله، داراى تحصيلات كارشناسى، شغل آزاد، ازدواج اول، مسكن اجارهاى، عدم مصرف دخانيات، فاقد فرزند، تأهل به مدت ه سال و سابقه بيمارى بودند. ميزان رضايت جنسى مردان متأهل شهر سنندج در حد مابين ضعيف تا متوسط گزارش شد. ولتن' و مركراف (Y.IV) ميانخين رضايت جنسى مردان را 49/OVV اعلام كردند كه كمتر از رضايت جنسى افراد مورد مطالعه در بثزوهش حاضر بود. لوكك و لوكه (Y.19) نيز در مطالعهاى متفاوت ميزان رضايت جنسى مردان داراى زوج نابارور را يايين گزارش كردند. بشارت

1. - Velten J \& Margraf J

${ }^{2}$ - Luk BH \& Loke AY 
IR.MODARES.REC.1398.038 مصوبه اخلاق در

يزّوهش و با حمايت مالى دانشگاه تربيت مدرس انجام

شد. نويسند كان مطالعه بر خود لازم مىداند كه از

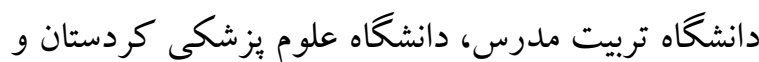

همجِنين مشاركت كنند گان جهت همكارى در اجراى

مطالعه حاضر تشكر و قدردانى نمايند. بنا بر اظهار

نويسند گان، اين مقاله تعارض منافع ندارد و هزينه اجراى اين يزّوهش توسط دانشگاه تربيت مدرس تأمين شده

\section{References}

Attaky A, Schepers J, Kok G, Dewitte M. (2021). The role of sexual desire, sexual satisfaction, and relationship satisfaction in the sexual function of arab couples living in saudi Arabia. Sex Med, 9(2), 100303.

Bahrami N, Sharif Nia H, Soliemani MA, Haghdoost AA. (2016). Validity and reliability of the persian version of Larson sexual satisfaction questionnaire in couples. Joumal of Kerman University of Medical Sciences, 23(3), 344356. (In Persian)

Bakhshayesh A, Mortazavi M. (2010). The relationship between sexual satisfaction, general health and marital satisfaction in couples. Joumal of Applied Psychology, 3(4), 73-85. (In Persian)

Besharat MA, Rafiezadeh B. (2016). Prediction of sexual satisfaction and marital adjustment levels according to job variables, commitment, intimacy, and sexual knowledge and attitude. Journal of Family Psychology, 3(1), 31-46. (In Persian)

Buczak-Stec E, Konig H-H, Hajek A. (2021). Sexual satisfaction of middle-aged and older adults: Longitudinal findings from a nationally representative sample. Age Ageing, 50(2), 559-564.

Calvillo C, Sanchez-Fuentes MD, Sierra JC. (2020). An explanatory model of sexual satisfaction in adults with a same-sex partner. An analysis
اهميت بيشترى دارد. اين امر مىتواند به دليل فرزندآورى و مسائل اقتصادى و عدم شناخت و صميمت كافى زوجين باشد. با اين حال، در مطالعه حاضر رابطه مدت زمان تأهل و رضايت جنسى مردان مورد بررسى قرار نخرفته است كه مىتواند موضوع مطالعات آتى باشد. همجنين، به دليل اهميت رضايت جنسى مردان در كنار رضايت جنسى زنان، برگزارى برنامههاى آموزش بهداشت جنسى مى توانند باعث بهبود رضايت جنسى و در نتيجه افزايش كيفيت زندكى زناشويى شوند (درگاهى، صدرى، قمرى، رضايى و نظرى، . IF. كريمى، داد گر، عافيت و رحيمى، بوسا ).

نتيجه كيرى نتايج حاصل از اين مطالعه، ميزان رضايت جنسى مردان را در سطح مابين ضعيف تا متوسط نسبت به روابط جنسى زناشويى نشان داد. در اين خصوص، بيشنهاد مىشود كه برنامهها و مداخلههاى آموزشى لازم براى افزايش آكاهى لهى مردان متأهل از روابط جنسى رضايت بخش از سوى مراكز مشاوره و سلامت جنسى در نظر كرفته و اجرا شود. از محدوديتهاى مطالعه حاضر، عدم باسخگُ بريى برخى از مردان متأهل به برسشنامه بود كه مىتواند ناشى از تابو بودن موضوع رابطه جنسى و رضايت از آن در بين افراد جامعه باشد. در اين خصوص، اهميت انجام مطالعه و تأثير آن بر افزايش كيفيت زندگى جنسى براى شركت كنند كان مطالعه در كنار ايجاد اطمينان از حفظ محرمانكى اطلاعات، تشريح شد.

سياسگز ارى اين مطالعه بخشى از يايان نامه دكتراى آموزش بهداشت

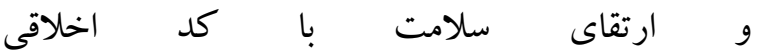


based on gender differences. Int J Environ Res Public Health, 17(10), 3393.

Dargahi S, Sadri E, Ghamari Givi H, Rezaei Sharif A, Nazari A. (2021). Effect of sexual relationship enrichment educational program on the sexual satisfaction of dual-career couples in Ardabil, Iran (2019): A case study. Joumal of Occupational Health and Epidemiology, 10(1), 57-63. (In Persian)

Dehghani Champiri F, Dehghani A. (2020). Predicting sexual satisfaction in Iranian women by marital satisfaction components. Sex Relation Ther, 1-15. (In Persian)

Del Mar Sanchez-Fuentes M, Santos-Iglesias P, Sierra JC. (2014). A systematic review of sexual satisfaction. Int J Clin Health Psychol, 14(1), 67-75.

Din HM, Akahbar SAN, Ibrahim R. (2019). The association between depression and sexual satisfaction among Malay elderly in Malaysia. Heliyon, 5(6), e01940.

Gewirtz-Meydan A, Finzi-Dottan R. (2018). Sexual satisfaction among couples: The role of attachment orientation and sexual motives. J Sex Res, 55(2), 178-190.

Ghofranipour F, Aminshokravi F, Torkashvand R. (2017). The relationship between demographic factors and marital satisfaction of couples intended to divorce referred to family Judicial Complex in Bonujerd county. Iranian Journal of Health Education and Health Promotion, 5(1), 43-50. (In Persian)

Karimi A, Dadgar S, Afiat M, Rahimi N. (2013). The effect of sexual health education on couples' sexual satisfaction. The Iranian Joumal of Obstetrics, Gynecology and Infertility, 15(42), 23-30. (In Persian)

Khamse F, Zahrakar K, Mohsenzade F. (2015). The effect of practical application of intimate relationship skills (PAIRS) on enhancing sexual satisfaction and marital happiness in married wives. Positive Psychology Research. Aug 23;1(2):52-41. (In Persian)

Khoei EM, Moeini B, Barati M, Soltanian AR, Shahpiri E, Ghaleiha A, Bagherikholenjani F. (2019). A qualitative inquiry of sexuality in
Iranian couples using the InformationMotivation-Behavioral skills paradigm. J Egypt Public Health Assoc, 94(1), 1-11. (In Persian)

Kim O, Jeon HO. (2013). Gender differences in factors influencing sexual satisfaction in Korean older adults. Arch Gerontol Geriatr, 56(2), 321-326.

Larson JH, Anderson SM, Holman TB, Niemann BK. (1998). A longitudinal study of the effects of premarital communication, relationship stability, and self-esteem on sexual satisfaction in the first year of mamiage. Joumal of sex \& marital therapy. 24: 193-206.

Luk BH, Loke AY. (2019). Sexual satisfaction, intimacy and relationship of couples undergoing infertility treatment. J Reprod Infant Psychol, 37(2), 108-122.

Mohebbi P, Kamali-Fard M, Berzenjeh Atri S, Safaeiyan A, Rastegari L. (2012). The quality of sexual health consultation provided in premarital counseling centers in Tabriz on the views of clients. J Nurs Midwif, 2(1), 23-30. (In Persian)

Pascoal PM, Narciso IdSB, Pereira NM. (2014). What is sexual satisfaction? Thematic analysis of lay people's definitions. Journal of sex research, 51(1), 22-30.

Rahmani A, Merghati-Khoei E, Moghaddam-Banaem L, Zarei F, Montazeri A, Hajizadeh E. (2015). Sexuality research in Iran: A focus on methodological and ethical considerations. Iran J Public Health, 44(7), 979-986. (In Persian)

Rahmani A, Safavi S, Jafarpoor M, Merghati-Khoei EA. (2010). The relation of sexual satisfaction and demographic factors. Iran Joumal of Nursing, 23(66), 14-22. (In Persian)

Rainer H, Smith I. (2012). Education, communication and wellbeing: An application to sexual satisfaction. Kyklos, 65(4), 581-598.

Rehman US, Rellini AH, Fallis E. (2011). The importance of sexual self-disclosure to sexual satisfaction and functioning in committed relationships. J Sex Med, 8(11), 3108-3115.

Shafi Abadi A, Honarparvaran N, Tabrizi M, Navabi Nezhad S. (2010). Efficacy of emotion- 


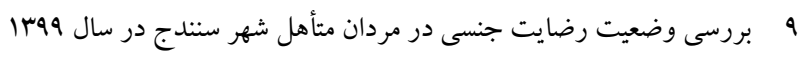

focused couple therapy training with regard to increasing sexual satisfaction among, couples. Journal of Thought and Behavior in Clinical Psychology, 4(15), 59-70. (In Persian)

Shahsiah M, Botlani S, Ahmadi SA, Bahrami F, Mohebbi S. (2010). Effect of attachmentbased couple therapy on sexual satisfaction and intimacy. Journal of fundamentals of mental health, 12(46), 496-505. (In Persian)

Sharyati M, Ghamarani A, Abbasi Molid H. (2010). The study of relationship between alexithymia and sexual satisfaction among female married students in Tabriz University. Joumal of Family Research, 6(21), 59-70. (In Persian)

Taghavi SA, Aramesh S, Azizi-Kutenaee M, Allan H, Safarzadeh T, Taheri M, Bazarganipour F. (2021). The influence of infertility on sexual and marital satisfaction in Iranian women with polycystic ovary syndrome: A case-control study. Middle East Fertil Soc J, 26(1), 1-7. (In Persian)

Tehrani F, Farahmand M, Mehrabi Y, Afzali H, Abedini M. (2011). Prevalence of female sexual dysfunction and its correlated factors: A population based study. Payesh, 11(6), 869875. (In Persian)

Velten J, Margraf J. (2017). Satisfaction guaranteed? How individual, partner, and relationship factors impact sexual satisfaction within partnerships. PloS one, 12(2), e0172855.

Ward DA, Kassenbaum GG. (2017). Women's prison: Sex and social structure. Routledge; Jul 28.

Yoo H, Bartle-Haring S, Day RD, Gangamma R. (2014). Couple communication, emotional and sexual intimacy, and relationship satisfaction. J Sex Marital Ther, 40(4), 275293.

Zarei M, Teiri F, Soufizadeh N, Haji-Esmaeelpour A, Gharibi F, Rasolabadi M. (2019). Evaluating the relationship between sexual function and marital satisfaction in maried Kurdish women in year 2016. Chronic Diseases Joumal, 7(1), 22-27. (In Persian)

Zegeye B, Woldeamanuel GG, Negash W, Shibre G. (2020). Sexual Satisfaction and Its Associated
Factors among Married Women in Northem Ethiopia. Ethiop J Health Sci, 30(2), 169-178. 